\title{
DE HISTORIADORES Y MÉTODOS
}

Javier Meza*

Escribir sobre historia y enseñarla: ése es, desde hará pronto treinta y cuatro años, mi oficio. Me ha llevado a hojear muchos documentos de diversas edades, para separar lo mejor que he podido la verdad de la mentira; también me ha llevado a mirar y observar mucho. Pues siempre he creído que el primer deber de un historiador, como decía mi maestro Pirenne, es interesarse 'por la vida'.

Marc Bloch

Marc Bloch es considerado por muchos el historiador más importante del siglo xx. Preocupado siempre, como él mismo decía, por una historia más amplia y más humana y que se expresara de la manera más sencilla para que la entendieran tanto los doctos como los profanos, sin duda, revolucionó los estudios históricos y la enseñanza de la historia. Sabía o estaba muy consciente de que "el gran drama del espíritu humano consiste precisamente en que se encuentra vinculado con la materia y la eterna angustia de todas aquellas personas que tienen algo que decir radica en no poder llegar a conseguirlo”. ${ }^{1}$ En el mismo sentido siempre insistió: “... el historiador no sólo debe escudriñar el pensamiento de los hombres, sino también el lenguaje que, con mucha frecuencia, resulta ser un intérprete excesivamente infiel de dicho pensamiento". ${ }^{2}$ Ideas muy parecidas también fueron externadas por el historiador Georges Duby al hablar-

\footnotetext{
* Departamento de Política y Cultura UAM-X.
} 


\section{JAVIER MEZA}

nos de las influencias que tuvo Bloch en su formación y lo trascendente que resultó para él leer los Annales d'histoire économique et sociale dirigidos por Bloch y Lucien Febvre. A su juicio de dichas lecturas obtuvo sobre todo dos importantes enseñanzas: por un lado que el historiador debe abordar otras disciplinas y jamás ser unidireccional y, por otro, que "llevar a cabo una investigación con todo el rigor que ello requiere no le obliga, a la hora de dar a conocer los resultados de su investigación, a escribir con frialdad, pues el sabio cumple tanto mejor su función cuanto más gusta a los que le leen, y los retiene y cautiva con los ornamentos de su estilo. ${ }^{3}$

La vida de Bloch, como francés y descendiente de judíos no fue nada fácil, pero también resulta apasionante. De sí mismo acostumbraba decir que por las mañanas era historiador y por las tardes filósofo. Pero, sin duda, además de ser un hombre profundamente teórico la vida lo obligó a ser un hombre profundamente práctico. Su contexto estuvo marcado tanto por los odios nacionalistas y racistas - esos 'dioses tribales’ promotores fáciles de la guerra-y por un profundo desprecio por la verdadera historia. Para muchos, el historiador era sólo un 'murciélago de erudición’ y, además hacía tiempo que la moda era considerar a la historia como un "simple juego intelectual, divertido y bastante banal”. Bloch opinaba que pertenecía a los vencidos de un tiempo injusto y, a pesar de todo o, por eso mismo, demostró siempre un profundo amor por la verdad y la justicia. Discípulo y admirador de Fustel de Coulanges (además de Emile Durkheim), de Bloch se puede decir lo que él mismo opinó sobre aquél. Por un lado, aplicar siempre al estudio de la historia la duda cartesiana y recomendar a los alumnos "si advierten alguna afirmación falsa por mi parte no dejen de señalarla, pues lo esencial es lograr establecer la verdad” y, por

${ }^{1}$ Marc Bloch, "Fustel de Coulanges, historiador de los orígenes de Francia, L’Alsace française”, t. XIX, 1930, p. 206-9 en Historia e historiadores, textos reunidos por Étienne Bloch, 1999, Madrid, Akal, p. 246.

${ }^{2}$ Ibid., p. 248.

${ }^{3}$ Georges Duby, La historia continúa, 1992, Madrid, Debate, p. 13. 


\section{HISTORIADORES Y MÉTODOS}

otro lado, estar siempre descontento con uno mismo por aspirar siempre a estar más cerca de la verdad. ${ }^{4}$ No en balde acostumbraba decir Coulanges que el oficio más penoso de todos era el de historiador. ${ }^{5}$ Quizá por eso uno de los libros más bellos de Bloch inicia con la implacable pregunta de uno de los sujetos más implacables: el niño. Pues, ciertamente, de un niño podemos aprender a reír, a llorar, a jugar y a estar siempre ocupados, pero también su afán desmedido por conocer y preguntar: "Papá, explícame para qué sirve la historia.” En sí, para el autor, la pregunta anterior no era nada ingenua pues ella interroga ni más ni menos acerca de la legitimidad de la historia y debe interesar a todo Occidente. ${ }^{6}$

Bloch también tuvo que enfrentar, entre otras cosas, el cientificismo positivista de su época que veía el quehacer histórico con desprecio rebajándolo a algo inútil por considerarlo poco científico y poco práctico. Como él mismo dice:

En las últimas décadas del siglo XIX, las generaciones inmediatamente anteriores a la nuestra vivieron como alucinadas por una imagen muy rígida, una imagen realmente comtiana de las ciencias del mundo físico. Extendiendo este esquema prestigioso al conjunto de las adquisiciones intelectuales, pensaban que

${ }^{4}$ Op. cit., p. 247. Respecto a Coulanges y sus enseñanzas también decía: "En la obra se aprecia un gusto por expresar sólo la verdad en toda su desnudez, libre de cualquier matiz, y un deseo por mostrar al lector el camino por el que se ha llegado a ésta, de tal modo que éste pueda, a su vez, seguirla y descubrir los falsos recodos de dicho camino cuando sea necesario. Estas dos preocupaciones del historiador son las que nos permiten reconocer las cualidades profundas de un alma. La obra es honrada porque su autor era honrado por encima de todo.” Ibid., p. 249.

${ }^{5}$ Marc Bloch, La historia rural francesa: caracteres originales. Suplemento compilado por Robert Dauvergne según los trabajos del autor (1931-44), 1978, Barcelona, Crítica, p. 27.

${ }^{6}$ Marc Bloch, Apología para la historia o el oficio de historiador, 1996, México, INAH y FCE, p. 121 s. 
JAVIER MEZA

no puede haber conocimiento auténtico que no desemboque en demostraciones, de entrada irrefutables, en certidumbres formuladas bajo el aspecto de leyes imperiosamente universales. Esta era una opinión más o menos unánime. ${ }^{7}$

Afortunadamente hacia principios del siglo XX 'la atmósfera mental' de la ciencia había cambiado. La teoría cinética de los gases, la mecánica einsteiniana, y la teoría de los quanta hicieron a la ciencia más flexible. En efecto, para Newton el tiempo y el espacio eran los mismos para todos los observadores; Einstein, en cambio, descubrió que más bien no existe un universal ahora sino más bien sólo hay un 'aquí y ahora' para cada observador lo cual significa que tampoco son iguales los tiempos y espacios entre ellos. Max Planck en 1900 encontró que, igual que la energía, la materia no es continua, "sino que aparece siempre como conjuntos o quanta de determinados tamaños”. Asimismo, en 1927 el físico alemán Werner Heisenberg halló que es imposible describir a la naturaleza con total certidumbre pues ella no es inamovible. Además, nunca podremos predecir el futuro de una partícula pues ni siquiera estamos seguros de su presente. En este sentido, "si queremos predecir con cierta exactitud su futuro, tenemos que admitir una cierta incertidumbre: un margen de alternativa, una ambigüedad -lo que los ingenieros llaman una cierta tolerancia." ${ }^{8}$ Desde estos momentos dejaban de existir las pretendidas ciencias exactas, ahora todo era inexacto y, por lo mismo, para Bloch desde la física hasta la historia todas eran simplemente ciencias en continua construcción, ciencias provisionales y nunca definitivas.

${ }^{7}$ Ibid., p. 129-30.

${ }^{8}$ Jacob Bronowski, El sentido común de la ciencia, 1978, Barcelona, Península, p. 74 s. El autor también señala algo sumamente importante: "En el fondo, pues, el principio de incertidumbre afirma en términos especiales lo que siempre se supo. La ciencia no es un modo de describir la realidad, por lo tanto está determinada por los límites de las observaciones, y no afirma nada que esté fuera del campo de la observación. Todo lo demás no es ciencia, es escolástica.” 
Marc Bloch nació el 6 de julio de 1886 en Lyon , su padre, Gustave Bloch, en la Facultad de Letras enseñaba la cátedra de Historia y Antigüedad Clásica. Eran descendientes de una familia judía llegada a Alsacia durante el siglo XVIII. En 1908 obtuvo la agregación de historia en la Escuela Normal de París. Posteriormente, entre 1908-9, permaneció un tiempo en Berlín y en Leipzig, lo que le permitió familiarizarse con los trabajos y métodos de la Escuela de Historia Alemana. Precisamente su actividad científica empezó entre 1911 y 1912. Antes de la Primera guerra mundial dio clases en los liceos de Montpellier y Amiens y en agosto de 1914 fue movilizado como sargento de infantería. Cuando terminó la Guerra ya era capitán y había obtenido cuatro menciones honoríficas y la Gran Cruz del mérito militar. Inmediatamente, en 1919, fue nombrado profesor adjunto de historia medieval en la Universidad de Estrasburgo, luego fue profesor asociado y, finalmente en 1927, profesor de historia medieval y maestro de conferencias. Fue en esta ciudad donde realizó su mayor obra como profesor e investigador pues permaneció en ella hasta 1936; aquí conoció a otro gran historiador y amigo de toda su vida Lucien Febvre y fue donde ambos fundaron, en 1929, los Annales d'histoire économique et sociale. Posteriormente, en 1936, fue designado profesor titular de Historia Económica en la Sorbona y maestro de conferencias. A petición propia, el 24 de agosto de 1939 fue movilizado como capitán de estado mayor. Luego de la derrota de Francia, en 1940 se le excluyó de todo servicio público por los decretos antisemitas del gobierno de Vichy. No obstante, fue rehabilitado "por los servicios científicos excepcionales prestados a Francia” y adscrito nuevamente a la Universidad de Estrasburgo, entonces replegada en Clermont Ferrand.

Posteriormente a causa de que su mujer tenía problemas de salud pidió y consiguió ser enviado a la Universidad de Montpellier. Ya desde Clermont Ferrand Bloch había establecido contactos con los grupos resistentes y en Montpellier contribuyó a la formación del movimiento a nivel regional y, en 1943, decidió pasar a la clandestinidad absoluta trasladándose a Lyon. El 8 de marzo de 1944 fue detenido por la Gestapo, a consecuencia de la tortura le rompen una muñeca, algunas 


\section{JAVIER MEZA}

costillas y lo someten a baños de agua helada hasta dejarlo en estado de coma. Finalmente, el 16 de junio de 1944, ya recuperado, lo suben a un camión junto con otros detenidos y a la orilla de un campo son fusilados. Bloch tenía 57 años. Un sobreviviente de la masacre cuenta que Bloch, el profesor e investigador que a juicio de George Duby “no era agradable de trato", en el camino hacia la muerte se pone a consolar a un joven que lloraba diciéndole: "Nos van a fusilar, no tengas miedo, no nos harán sufrir... esto acabará rápido.” Sin duda, Bloch no tuvo miedo a la muerte, durante los últimos años, en un cuaderno de apuntes, anotó en forma de epígrafe, entre otros, una cita de Lameennais que dice: "siempre estará incompleta una vida hermosa que no acabe en el campo de batalla, el patíbulo o la cárcel”.9

La anterior cita, sin duda, bien podía haber sido el merecido epitafio para un gran historiador rebelde en cuyo testamento él mismo sugería que, en caso de necesitarlo, estaría bien en su lápida la frase Dilexit veritatem. Amor por la verdad fundamentado en la elección y en la reflexión y que, obviamente, implica defender lo más importante que puede poseer todo ser humano: la dignidad -de la que no Walter Scott observará, es algo que nadie nos la puede dar pero que tampoco nos la puede quitar. Bloch lo anterior lo vivió plenamente pues siempre fue consecuente de palabra y de acto con lo que alguna vez dijo: "Toda mi vida he tratado de alcanzar una sinceridad absoluta de la expresión y del espíritu. Considero la complacencia con la mentira, por muchos pretextos con que se adorne, la peor lepra posible del alma."10 En efecto, ser indiferente ante la mentira o bien defenderla es no poseer dignidad, cosa muy grave, máxime cuando se pretende ejercer el oficio de historiador.

Bloch entre 1911 y 1923 trabajó su primer libro: Los reyes taumaturgos (1924). Luego de esta publicará múltiples artículos y dos libros

${ }^{9}$ Marc Bloch, La extraña derrota, prólogo de Stanley Hoffmann, 2003, Barcelona, Crítica, p. 17.

${ }^{10}$ Marc Bloch, “El testamento de Marc Bloch”, en La extraña derrota, op. cit., p. 169. 
más: Los caracteres originales de la historia rural francesa (1931) y La sociedad feudal (1939-1940). Los caracteres nació gracias al Instituto para el Estudio Comparativo de la Civilizaciones, de Oslo que, en 1929, tuvo la confianza y el atrevimiento de pedirle a un joven Bloch en el umbral de su carrera algunas lecciones sobre la historia rural francesa. Georges Duby dijo que con ese libro fue el inventor de la Antropología histórica, es decir, de la historia de las mentalidades. Jacques Le Goff también opinó que Los reyes taumaturgos constituían un modelo de antropología política histórica. Pero prácticamente todo el mundo está de acuerdo en que sus trabajos e ideas revolucionaron el oficio de historiador por su "gran receptividad a los fenómenos asociados a las mentalidades, antropología, la sociedad y la economía” y por insistir en la necesidad de efectuar análisis históricos sincrónicos y comparativos.

En efecto, Marc Bloch fue ante todo un gran historiador comparatista. Es decir, un historiador capaz, como dijera Lucien Febvre, de "movilizar tantas aptitudes y fecundar unos con otros tantos conocimientos diversos", 11 para encontrar la verdad. Pues creía que el deber de toda ciencia, física o humana, tenía como objetivo primordial encontrar la verdad para lograr aproximar a los seres entre sí. De ahí que siempre estuvo convencido que en historia "la verdad sólo se llega a descubrir mediante la comparación de los diferentes testimonios entre sí”. ${ }^{12} \mathrm{Y}$ en consecuencia afirmaba: "Nos hemos hecho una ley de no temer repetirnos”, y en efecto, así ocurre con sus propuestas acerca del método comparativo aun cuando siempre es posible encontrar en ellas el enriquecimiento o el cambio de matices.

La difusión y el uso del método comparativo no deja de constituir una respuesta a las masacres e intolerancias de la Primera guerra mundial. Precisamente en 1930 Bloch escribió un artículo intitulado "Un centro de estudios en desarrollo: El Instituto para el Estudio comparado de las civilizaciones de Oslo."13 En él nos comenta que los pueblos

${ }^{11}$ La historia rural..., op. cit., p. 13.

${ }^{12}$ Historia e historiadores..., op. cit., p. 25. 
JAVIER MEZA

nórdicos se inclinaron por la imparcialidad y, después de la guerra, se preocuparon por establecer una cooperación científica internacional buscando un 'horizonte intelectual amplio’. Pero es más, ya desde 1917 el profesor Fredeng Stang buscó convertir a escandinavia en un sitio de asilo para poder desarrollar un trabajo científico a nivel internacional. Así, primero en 1919, se fundó un Fondo Estatal de Investigaciones y, posteriormente, el Instituto para el Estudio Comparado de las Civilizaciones siendo uno de sus objetivos fundamentales, tal y como su nombre lo indica, tomar como campo de estudio a toda la humanidad sin límites o fronteras. Este objetivo fue retomado por los Annales en 1928, es decir, poco antes de que se fundaran.

Una razón que tenían los noruegos para impulsar este tipo de estudios era que la ciencia escandinava desde hacía tiempo realizaba investigaciones sobre aspectos lingüísticos, etnográficos y arqueológicos. Pero también porque en esos momentos, al igual que hoy, era muy importante situarse por encima de las fronteras nacionales y sus absurdos odios y creencias. Bloch, como historiador comparatista siempre creyó en lo anterior, de ahí que en múltiples ocasiones insistiera sobre la importancia de la historia, pues a ésta irresponsablemente en un tiempo se le tuvo "como un simple juego intelectual, divertido y bastante banal". Y no se reconocía o diferenciaba que el pasado por sí mismo no es edificante porque "el auténtico medio de educación lo constituye el estudio del pasado”. Ya que él constituye ‘la aventura común’ que todos hemos vivido y cuyo recuerdo debe servir para unirnos y aproximarnos..., y nunca para distanciarnos. Pues "la humanidad, al igual que el individuo, sólo puede llegar a tomar conciencia de sí misma recordando, es decir, por medio de la historia”. ${ }^{14}$ Aunque, desgraciadamente, "parece que es cuando los hombres dejan de estar de acuerdo cuando su historia se hace clara”. Además, debemos tomar en cuenta que siempre:

${ }^{13}$ Ibid., p. 67. 
las actuales fronteras políticas son incapaces de encerrar dentro de sus límites a los grandes problemas que constituyen la trama de la historia humana, resulta igualmente cierto que la percepción de las diferencias entre las diversas colectividades sólo se puede obtener mediante una perpetua confrontación. ${ }^{15}$

En esos momentos los mejores frutos que el método comparativo impulsado por los escandinavos había logrado se daban en el campo de la lingüística, la arqueología, el folclore y en el estudio de las mal llamadas civilizaciones primitivas árticas. Pero también, precisamente entre 1924 y 1928, se desarrollaron misiones lingüísticas en Afganistán y se realizó un proyecto en el Cáucaso cuyo objeto era la exploración etnográfica de la península de Kola. Por todo lo anterior, para Bloch no existía ninguna duda que para el estudio de las sociedades europeas debía utilizarse el utillaje comparativo forjado por los lingüistas y etnógrafos. Asimismo, era necesario impulsar la creación de una Bibliografía Internacional de Ciencias Históricas, la cual era posible gracias al desarrollo de las síntesis de historia nacional que no podían dejar de hablar de las relaciones existentes entre el país estudiado y sus vecinos. Partiendo de ellas se podrían estudiar fenómenos que desbordaban las fronteras de Estados y Naciones. Sin embargo, Bloch también insistía, que aun cuando él fuese un adepto declarado del método comparativo e inclinado a los amplios horizontes, tampoco se debía ser indiferente y dar por concluida la historia nacional.

La defensa de Marc Bloch del método comparativo obviamente la encontramos en toda su obra pero insistiendo siempre en que, aun cuando el futuro de la ciencia histórica pudiera encontrarse en él, debemos recordar que en la ciencia no existen talismanes. Además, dicho método se debía perfeccionar y generalizarlo. Básicamente resultan de sumo interés dos de sus artículos al respecto. Uno fue escrito en 1928 e intitulado "A favor de una historia comparada de las civiliza-

${ }^{14}$ Ibid., p. 259 y 264.

${ }^{15}$ Ibid., p. 69. 
JAVIER MEZA

ciones europeas”, y el otro, “Comparación” en 1930. Sin duda, como el autor nos señala, la palabra comparativo no ofrece ningún problema. Comparar significa "aproximar dos o más cosas para determinar sus similitudes y diferencias”. La definición tiene la ventaja de insistir sobre semejanzas y diferencias, lo cual para Bloch es sumamente importante sobre todo a nivel de diferencias, pues son éstas las que realmente nos señalan o nos indican la existencia de los problemas que deben preocupar al historiador. Un fenómeno social puede pasar desapercibido y sólo cobra fuerza cuando la comparación, gracias a las diferencias, nos lo resalta como algo importante. En otras palabras, en una sociedad un fenómeno se puede manifestar con mucha amplitud y resulta fácil de descubrir. Pero en cambio, en otra sociedad a pesar de haber existido también dicho fenómeno no se percibe por diferentes causas, como puede ser falta de documentación o porque simplemente esta sociedad tiene una constitución política y social distinta. El método comparativo encontró su consolidación gracias a la lingüística y su capacidad para tratar a una lengua como un conjunto aislado capaz de compararse con otro. Al respecto Bloch nos dice que:

En la actualidad, la lingüística comparada puede plantearse como una de sus tareas esenciales la puesta de manifiesto de los rasgos originales de las distintas lenguas. Pero en realidad su principal esfuerzo se ha orientado, ya desde sus inicios, hacia un objetivo totalmente distinto: la determinación de los parentescos y de las filiaciones entre las lenguas, es decir, la búsqueda de las lenguas madres. La delimitación del grupo indoeuropeo original, y la reconstrucción, sin duda alguna hipotética pero basada en conjeturas seguras, del indoeuropeo original en sus rasgos fundamentales son algunos de los triunfos más brillantes de un método basado en la comparación. ${ }^{16}$

Entre las principales ventajas para el quehacer histórico que el método comparativo presenta encontramos las siguientes propuestas de Bloch. Una va en el sentido de que él nos ayuda a romper con los 


\section{HISTORIADORES Y MÉTODOS}

límites impuestos por las fronteras políticas y nos permite estudiar las diferencias entre dos o más sistemas sociales. Por eso es necesario romper con los ‘anticuados compartimientos topográficos’ con que se pretende encerrar las realidades sociales. En este sentido Bloch se preguntó: “¿en qué época y lugar se ha visto que los fenómenos sociales hayan detenido su evolución y desarrollo dentro de los mismos límites que sirven para delimitar con total precisión los dominios políticos o nacionales?"17 También consiste en "buscar las similitudes y las diferencias entre una serie de fenómenos de naturaleza análoga que han sido tomados de diferentes medios sociales con el objeto de explicarlos", ${ }^{18}$ por lo cual resulta ideal para las investigaciones minuciosas y de detalle. Pero para realizar lo anterior hacen falta dos condiciones: por un lado, que existan ciertas similitudes en los hechos observados y, por otro, "una cierta diferencia entre los medios en que ambos han tenido lugar”. ${ }^{19}$ En otras palabras, los fenómenos seleccio-

16 “A favor de una historia comparada de las civilizaciones”, en Historia e historiadores, op. cit., p. 139. Acerca de la preocupación de Bloch porque la lingüística comparase las diferencias entre las distintas lenguas me parece atinado citar lo siguiente que, además, como veremos más adelante, tiene que ver directamente con el imaginario y la concepción del tiempo pasado/ presente/futuro: "La distinción pasado/presente/(futuro), que parece de carácter natural, no es universal en lingüística. Lo observaba ya Ferdinand de Saussure: 'La distinción de los tiempos, que nos es tan familiar, es ajena a algunas lenguas; el hebreo no conoce ni siquiera la distinción fundamental entre pasado, presente y futuro. El protogermánico no tiene una forma propia de futuro... Las lenguas eslavas distinguen regularmente dos aspectos del verbo: el perfectivo presenta la acción en su totalidad, como un punto, fuera de todo devenir; el imperfectivo la muestra en cambio en su hacerse, y en la línea del tiempo...' La lingüística moderna retoma la constatación: ‘ A menudo se supone que la misma triple oposición de los tiempos es un rasgo universal del lenguaje. Pero esto no es verdad'.” Véase Jacques Le Goff, Pensar la historia, 1991, Barcelona, Paidós, p. 178.

${ }^{17}$ Historia e historiadores..., op. cit., p. 143. 
JAVIER MEZA

nados de diferentes conjuntos deben tener entre sí ciertas analogías, como Bloch lo explica con el siguiente ejemplo:

Las diversas formas que revisten las relaciones vasalláticas y feudales de la Europa occidental y central en la Edad Media expresan ciertas necesidades e ideas extensibles a todo un grupo de sociedades. Los hechos similares que aparecen en cada una de estas diferentes series, tomadas de medios vecinos, sincrónicos y emparentados, se deben de explicar como consecuencia de un mismo origen, como producto de influencias recíprocas o, en definitiva, como similitudes evolutivas que básicamente explican las analogías territoriales que existen dentro de la estructura de cada uno de los sistemas en cuestión. ${ }^{20}$

Resumiendo de manera apresurada, digamos que el método comparativo entre otras ventajas presenta su capacidad para sugerir investigaciones, también su capacidad para explicar las supervivencias y para realizar la interpolación entre las curvas de evolución, igualmente nos capacita para investigar influencias y establecer filiaciones, y nos permite encontrar similitudes y diferencias "evolutivas para buscar las causas de las mismas”. En el caso de las supervivencias Bloch nos alerta acerca de algunos peligros que pueden surgir al utilizar la comparación. Una supervivencia es un fenómeno que se conserva como algo extraño en el medio general. En sus propias palabras debemos entender como supervivencias "a todas aquellas costumbres que, habiéndose conservado y llegado a cristalizar tras la desaparición del medio psicológico en que originalmente habían nacido, se nos aparecerían

18 “La comparación”, en Historia e historiadores, op. cit., p. 108. De este artículo también existe una versión en Perspectivas de la historiografía contemporánea, 1976, México, SepSetentas, p. 23-33.

${ }^{19}$ Véase “A favor de una historia comparada”, en Historia e historiadores, op. cit., p. 115.

${ }^{20}$ Ibid., p. 108. 
HISTORIADORES Y MÉTODOS

como irreductiblemente extrañas si el examen de casos similares en el seno de otras civilizaciones no nos permitiese reconstruir con precisión ese medio desaparecido". El caso que cita es "la muerte ritual en el santuario del bosque de Nemi”, caso que no dejó huellas ni en las instituciones que le vieron nacer ni en las mentalidades. En los inicios del Imperio romano muy cerca de Roma, a las orillas del lago de Nemi, acontecía un rito bastante cruel que consistía en que todo el que quisiera convertirse en sacerdote del templo de Diana que allí se encontraba tenía que dar muerte al servidor cuyo lugar iba a ocupar. Bloch, al respecto, acepta la propuesta de James Frazer planteada en su obra The Golden Bough:

Si podemos mostrar que siempre ha existido una costumbre bárbara similar a la de Nemi; si podemos descubrir los motivos que han dado origen a esta institución y demostrar que éstos han ejercido una influencia muy amplia y quizá universal en el seno de las sociedades humanas que dio origen, en circunstancias muy variadas, a un gran número de instituciones muy diferentes pero genéricamente parejas; si podemos encontrar, en definitiva, los trazos de su funcionamiento incluso en la Antigüedad clásica... entonces legítimamente podemos inducir que fueron estos mismos motivos los que han dado nacimiento, en una época muy lejana, al sacerdocio de Nemi. ${ }^{21}$

Bloch no deja de reconocer que el trabajo de Frazer constituye un buen ejemplo ‘ilustre e instructivo' de recopilación de documentos y testimonios de diferentes partes del mundo, sin embargo, tal tipo de comparación en algunos casos nos puede llevar a falsas explicaciones y conclusiones, o bien,

${ }^{21}$ James Frazer, La rama dorada, 1978, México, FCE, p. 10. Citado por Marc Bloch en op. cit., p. 136. 
JAVIER MEZA

dicho de un modo simple, este método comparativo de largo alcance es esencialmente un procedimiento de interpolación de curvas evolutivas. Su postulado, al igual que la conclusión que siempre alcanza, es la unidad fundamental del espíritu humano o, si se prefiere, la monotonía, la asombrosa pobreza de recursos intelectuales de que ha dispuesto la humanidad en el curso de su historia y particularmente la humanidad primitiva en los tiempos en que, por hablar como sir James Frazer, elaboraba, en su simplicidad primigenia, su filosofía de la vida. $^{22}$

Al respecto también Bloch nos dice que la historia comparada extensa viene a ser a nivel de lingüística como los estudios de lingüística general y, en cambio, el estudio paralelo de sociedades vecinas con un horizonte más limitado es equivalente a la lingüística histórica (como el caso de la lingüística indoeuropea). Y, sin duda, el último caso es más científico, pues "se trata de una tipología mucho más capacitada para realizar rigurosas clasificaciones y criticar las realizaciones existentes y que, al mismo tiempo, parece permitir la posibilidad de alcanzar conclusiones que, a la vez, resultan menos hipotéticas". ${ }^{23}$

De acuerdo con lo anterior, es claro que Bloch siempre estuvo preocupado por aplicar el método comparativo sin salirse de la civilización europea, del mundo europeo, y que él define de la siguiente manera:

El mundo europeo, en tanto que europeo, es una creación de la Edad Media, que casi al mismo tiempo, rompe la unidad, al menos relativa, de la civilización mediterránea y arroja, de forma desordenada y dentro del mismo crisol, a los pueblos ya romanizados con aquellos que Roma nunca había llegado a conquistar. Fue en este momento cuando nació Europa, en el

${ }^{22}$ Marc Bloch, Historia e historiadores, op. cit., p. 116 y 117.

${ }^{23}$ Ibid., p. 117. 


\section{HISTORIADORES Y MÉTODOS}

sentido humano de la palabra; una Europa que, es preciso indicar, no coincide en nada con las divisiones artificiales que nos ofrecen ciertas geografías totalmente pasadas de moda. Digamos si se quiere, y por fijar las ideas, que se trata de la unidad histórica constituida, de manera innegable, por la Europa occidental y central. Este mundo europeo así definido nunca dejó, desde entonces, de ser recorrido por corrientes comunes. Europeos son el señorío, el vasallaje y las revoluciones urbanas; europeo es también el régimen parlamentario bajo su primera forma, caracterizada en todos los países por el sistema de 'Estados’ generales o provinciales; europeas son también las crisis monetarias, lentas o bruscas, que en tantas ocasiones han sacudido al edificio social hasta sus cimientos... Resulta evidente, por tanto, que la historia de las sociedades de las que hemos surgido, estudiadas en su estructura íntima, se debe de contemplar en un plano europeo; que la historia preocupada por poner de manifiesto los diferentes elementos de la constelación europea, tanto las diferencias como las similitudes, sólo puede ser historia comparada... ${ }^{24}$

Como historiador comparatista, Bloch sabía la importancia de la erudición, de ahí que su obra nos enseña el estudio detallado, crítico y sólidamente documentado. Mi ventaja ante otros historiadores, dijo en una ocasión, es muy modesta e impersonal, pues sólo consiste en que he leído una amplia bibliografía sobre los temas que me preocupan y, además, he utilizado siempre "una vara de zahorí muy eficaz: el método comparativo”. Quizá por lo anterior también reconocía que este método, por desgracia, estaba reservado a "una pequeña parte de los historiadores”. A Europa, como antes señalamos, la veía como un espacio con límites y consideraba que, por lo mismo, las técnicas de documentación que ella ofrecía no eran insuperables.

${ }^{24}$ Ibid., p. 150. 


\section{JAVIER MEZA}

En su primer libro, Los reyes taumaturgos (1924), analizó series paralelas en más de dos países. Es decir, estudio la evolución y el desarrollo de la realeza sagrada y milagrosa tanto en Francia como en Inglaterra empleando fuentes de ambos países en su mayoría inéditas con resultados que todavía hoy resultan imprescindibles de conocer para entender la gestación occidental moderna tanto del poder temporal como del espiritual y las aspiraciones de ambos a considerarse como sagrados. En efecto, aproximadamente desde el año 1000 apareció primero en Francia y un siglo después en Inglaterra la concepción de que los reyes, además de ser sagrados, eran taumaturgos o capaces de realizar curas milagrosas. Aproximadamente desde esas fechas durante muchos siglos los reyes de ambos países se especializaron sobre todo en tocar el llamado mal de escrófulas (posiblemente una adenitis tuberculosa o inflamación de los ganglios linfáticos) buscando sanar a los que lo padecían. Los reyes de Inglaterra también empezaron a distribuir entre sus súbditos y más allá de sus territorios anillos consagrados por ellos (cramp-rings) y que, supuestamente, tenían la facultad de curar la epilepsia y calmar los dolores musculares. Para Bloch los anteriores ritos de curación no podían estudiarse "separados de todo ese conjunto de supersticiones y leyendas que constituye lo maravilloso monárquico”. Hacer lo contrario era sólo ver en ellos ridículas anomalías desligadas de la conciencia colectiva y quitarle toda importancia. Cuando, a su juicio, el fenómeno de la denominada 'realeza mística' domina el desarrollo de todas la instituciones europeas y, si bien no le resultaba posible estudiarlo desde el origen simplemente porque muchas de sus causas resultaban inalcanzables, sí le era posible estudiarlo en su ‘evolución y perduración’ como algo más que una 'simple supervivencia' ya que sus manifestaciones se adaptaban a condiciones políticas y religiosas nuevas.

Por la fuerza misma de las cosas, este ensayo de historia política debió adoptar la forma de un estudio de historia comparada; pues Francia e Inglaterra por igual contaron con reyes médicos, y en cuanto a la realeza maravillosa y sagrada, ella fue 
común a toda la Europa occidental: circunstancia feliz, sí como creo, la evolución de las civilizaciones de las que somos herederos, sólo se nos presentará más clara el día que sepamos considerarlas fuera del marco demasiado estrecho de las tradiciones nacionales. ${ }^{25}$

Bloch siempre advirtió que detrás de todo hecho histórico existe un hecho psicológico, en el caso de las escrófulas o el mal del rey como se le decía en Francia o Kings Evil en Inglaterra ello es sumamente notorio. Por un lado el enfermo deseaba curarse y estaba dispuesto a recurrir al remedio que se le propusiera, por otro, los discursos apologéticos del poder y lo sagrado siempre han sido capaces de explotar todo tipo de necesidades en su provecho y a la medida de su conveniencia. El surgimiento de la realeza sagrada se pierde en el origen de los tiempos. En el caso de Europa, por ejemplo, en toda la Germania anterior al cristianismo parece que la realeza poseía un carácter religioso, pero también ocurría lo mismo con daneses, noruegos y suecos. Los emperadores romanos tampoco fueron la excepción, a Augusto, Vespasiano y Adriano, también se les consideró taumaturgos y sagrados. Sin embargo, los antiguos cultos fueron sustituidos por la civilización cristiana alrededor de los siglos VII y VIII, y ahora, gracias a una nueva institución, los soberanos adquirieron su carácter de sagrados. Ella fue "la consagración eclesiástica del advenimiento, y más particularmente su rito fundamental, la unción”. Se sabe que la unción fue resca-

${ }^{25}$ Marc Bloch, Los reyes taumaturgos, presentación de Marcos Lara, 1988, México, FCE, p. 28-9. El subrayado es nuestro. Como ya antes señalamos, para Bloch el nacionalismo con sus mezquinas y estrechas miras no hacía más que entorpecer las ricas posibilidades del método comparativo. Pensaba, por ejemplo, que simplemente debería existir un préstamo internacional bien organizado de libros y manuscritos, pues no se engañaba de que "la presente situación europea, poco propicia a los viajes y las adquisiciones de libros extranjeros por bibliotecas públicas y privadas hace más dificultosas que nunca las investigaciones de historia comparada”. Ibid. 
JAVIER MEZA

tada por el cristianismo apoyándose en la Biblia, la cual, a su vez, la había recogido de antiguas civilizaciones sirias o cananeas. Se consideraba que mediante la unción un cuerpo profano obtenía la categoría de sagrado: el rito consistía en ungir ciertas partes del cuerpo con un óleo santo (supuestamente había sido bajado del cielo por el Espíritu Santo o por un ángel en forma de paloma dentro de una redoma) e imponer una corona que era un viejo símbolo originario de las monarquías orientales. De esta manera el rey se convertía en 'Cristo del Señor', no obstante, para que esto fuera posible era necesaria la existencia de un sacerdote, lo cual ni más ni menos significaba el predominio del poder espiritual sobre el temporal. Claramente así lo indicaba la Iglesia: "La dignidad de los pontífices es superior a la de los reyes; pues los soberanos son consagrados reyes por los pontífices, mientras que los pontífices no pueden ser consagrados por los reyes.”26

Respecto a la curación de las escrófulas Bloch comprobó que en la Francia de las antiguas dinastías de los merovingios y carolingios aun cuando éstos supuestamente eran capaces de sanar ciertas enfermedades, no se menciona nada en relación con aquéllas. Más bien 'el milagro real' surgió con Roberto el Piadoso, segundo representante de una nueva dinastía, y quien obtuvo el título real y la unción en 987, viviendo todavía su padre Hugo Capeto. La dinastía capeta estaba mal consolidada y posiblemente para legitimarse recurrió al pretendido milagro de curar las escrófulas. Aproximadamente un siglo después en Inglaterra apareció el mismo fenómeno con el rey Enrique II (monarca que murió en 1189), y es posible que la casa real haya plagiado a los capetos. La capacidad de curar enfermedades pasó de Roberto el Piadoso a todos sus sucesores, y poco a poco, de generación en generación, se fue perfilando que el tacto real sólo era capaz de aliviar las escrófulas. Lo sobresaliente del asunto es que el supuesto poder de curar las escrófulas no haya aparecido como algo propio de un solo rey sino más bien como un privilegio de la casta real en general.

${ }^{26}$ Citado por Marc Bloch en Historia e historiadores, op. cit., p. 75. 
La oposición organizada de la Iglesia a que el poder temporal se revistiera con un carácter religioso surgió poco después de establecerse en Francia el rito de curación. Dicho movimiento fue producto de una obra colectiva durante el siglo XI, sin embargo normalmente se le conoce como gregoriano debido al papa Gregorio VII. Para Bloch no existe ninguna duda de que los reformadores gregorianos buscaron sobre todo

...despojar de su aura sobrenatural a estos príncipes mundanos que se creían personajes sagrados, reducirlos a no ser más que simples seres humanos -pensaran como pensaran sus fieles-, cuyo imperio sólo debía limitarse a las cosas terrenales. He ahí por qué, mediante una coincidencia que sólo en apariencia resulta paradójica, los partidarios del origen popular del Estado, los teóricos de una especie de contrato social, tienen que ser buscados en esta época entre los defensores más fanáticos de la autoridad en materia religiosa. ${ }^{27}$

Ciertamente, para Bloch era claro que el movimiento gregoriano buscó someter el poder temporal al espiritual, pero también a su juicio constituyó un esfuerzo supremo por destruir la confusión que existía y deslindar lo temporal de lo espiritual. En este sentido Gregorio VII quiso despojar de todo aspecto sagrado al poder temporal y sacralizar más el de la Iglesia, de ahí que negase a los reyes el don del milagro e incitará a los creyentes a rechazar la idea de que la realeza era sagrada. Se argumentó que en el rito de curación lo efectivo era la señal de la cruz y no el rey. Además, el rey no podía ser considerado como sacerdote porque no podía ser ordenado, no poseía el poder del exorcismo

${ }^{27}$ Ibid., p. 119. En muchos sentidos es obvio que la crítica de la Iglesia a los príncipes no estaba motivada precisamente por un 'amor democrático' hacia el pueblo sufriente, sino más bien por una rivalidad respecto a ver quién podía controlar las dos espadas, es decir, el poder espiritual y el temporal. 
JAVIER MEZA

para expulsar demonios, y ‘su mujer y su espada’ le impedían ser monje. En la misma línea se buscó que el rito episcopal fuese más complicado que el real e incluso, en el siglo XIII, se pretendió implantar que sólo el cura comulgase con las dos especies (vino y pan). Sin embargo, la medida no pudo cobrar efecto sobre el emperador, a pesar de todo, la Iglesia siempre insistió en que el que bendice es más grande que el bendecido. $^{28}$

En esta lucha política sobresale el hecho de que prácticamente no existan testimonios de los enfermos que den fe de haber sanado gracias al tacto real. Sin duda, como suele ocurrir, para los poderosos eso era lo menos importante. Además, quienes no podían ser engañados era lógico que opinasen al respecto como lo hizo el médico aragonés iniciador del descubrimiento de la llamada circulación pulmonar de la sangre, Miguel Servet (1511-53). Escribía al respecto en 1535: "Yo he visto con mis propios ojos cómo el rey tocaba a varios enfermos de esta afección. Si fueron efectivamente curados, eso yo no lo vi." 29 Sin embargo, a diferencia de Servet y otros pocos, resulta normal que la mayoría de los individuos se nieguen a mirar a sus reyes o gobernantes como hombres simples y corrientes. Si algo sobresale magistralmente en las obras de Marc Bloch es la demostración de que en los acontecimientos históricos está siempre presente la suma de lo individual y lo colectivo y, máxime, en el acontecimiento religioso. El mismo nos indica que normalmente hay dos tipos de explicaciones respecto al fenómeno religioso: una lo ve y pretende explicarlo como el producto genial de una mente individual, la otra más bien busca en él fuerzas sociales colectivas y espontáneas, pero ambos puntos de vista no son contradictorios:

${ }^{28}$ Ibid., p. 192 s. Acerca del conflicto entre las dos espadas véase de Walter Ullman Principios de gobierno y política en la Edad Media, 1971, Madrid, Revista de Occidente; e Historia del pensamiento político en la Edad Media, 1983, Barcelona, Ariel.

${ }^{29}$ Citado por Marc Bloch en Historia e historiadores, op. cit., p. 300. 


\section{HISTORIADORES Y MÉTODOS}

Para que una institución que se destina a servir objetivos precisos marcados por una voluntad individual pueda imponerse a todo un pueblo, es necesario que sea transportada por la corriente profunda de la conciencia colectiva; y acaso, recíprocamente para que una creencia un poco vaga pueda concretarse en un rito regular, no es indiferente que algunas voluntades claras le ayuden a cristalizar. La historia de los orígenes del tacto real, si es que pueden aceptarse las hipótesis que he presentado, merecerá incluirse entre los ejemplos ya numerosos de una doble acción de esta clase que el pasado suministra en abundancia. $^{30}$

Las causas de la desaparición del tacto real es posible encontrarlas en las revoluciones políticas ocurridas primero en Inglaterra y luego en Francia, pero también en el esfuerzo intelectual por excluir del mundo lo sobrenatural y fortalecer instituciones políticas racionales. No obstante, llama la atención la eterna obsesión del poder por recubrirse a sí mismo de una imagen sagrada. Bloch señala diferentes polémicas ocurridas durante el siglo XVII en donde se pretende demostrar que la figura del rey es una especie de ‘persona mixta y eclesiástica’. Sin duda, gracias a la Reforma protestante la figura real se había visto nuevamente fortalecida ante el poder de la Iglesia y por ello no resulta casual encontrar el renacimiento y modernización de discursos cuyos objetivos claramente son divinizar más la figura de los monarcas. Precisamente en Inglaterra durante la época de los Tudor se va a desarrollar la teoría de los Dos Cuerpos del Rey y la monarquía geminada. Según está concepción el rey posee un Cuerpo natural y un Cuerpo político indivisibles. El Cuerpo político posee cualidades y fuerzas misteriosas (es semejante a los ángeles y santos espíritus) y actúa sobre el Cuerpo natural mitigando sus dolores y corrigiendo los errores que éste pueda cometer. Pero además, cuando el rey muere lo único que muere con él es su Cuerpo natural pues el Cuerpo político, como es inmortal, se

${ }^{30}$ Ibid., p. 87. 


\section{JAVIER MEZA}

traslada al nuevo monarca. Esta concepción teológica-política conserva su influencia incluso hasta nuestros días. ${ }^{31}$

En La historia rural francesa (1931), Bloch interpretó la historia agraria, sobre todo de la Francia actual, Bélgica, La Renania y Suiza, encontrando, por un lado, en países como Inglaterra, Francia septentrional y central, en casi toda Alemania, y en una gran parte de Polonia y Rusia explotaciones fragmentadas, campos estrechos, alargados y sin cercar. En concreto, un paisaje totalmente diferente a los campos casi cuadrados del mediodía francés y a los cercados de las regiones occidentales de Francia e Inglaterra. Todo sin descuidar, principalmente, el estudio de las técnicas agrícolas, las realidades económicas y los modos de vida. No obstante, para él, según enfatiza, en esos momentos era más importante enunciar las cuestiones que tratar de resolverlas destacando tanto los caracteres comunes como las originalidades, pues la Francia rural en particular, es grande y compleja, y en ella se pueden ver claramente 'vestigios de civilizaciones agrarias opuestas'. Y precisamente la falta de estudios sobre el tema hacía que él insistiera más en lo general que en lo particular. ${ }^{32}$ Acerca de este libro Lucien Febvre escribió en 1932:

Señala el advenimiento de una historia rural que, mediando entre la historia de la técnica agrícola, la del régimen dominical

${ }^{31}$ El estudio de la monarquía geminada fue desarrollado magistralmente por el historiador de las ideas políticas Ernst H. Kantorowicz en Los dos cuerpos del rey. Un estudio de teología política medieval, 1985, Madrid, Alianza.

${ }^{32}$ Bloch al respecto afirmaba que "sólo la colaboración de numerosos trabajadores provinciales podía permitir elaborar, poco a poco, la historia de nuestros campos", y agregaba que se debía "seguir con simpatía la gran labor de minuciosos estudios que, sin ruido, se van llevando a cabo en nuestra provincia... Todos nosotros, los historiadores de oficio dedicados generalmente a investigaciones de más amplio radio, tenemos gran necesidad de esos pacientes roturadores”. Citado por Robert Dauvergne en La historia rural..., op. cit., p. 32. 
y la de la evolución comparada de los pueblos europeos, va a ser durante mucho tiempo uno de los campos de estudio más fecundos del ámbito histórico, uno de los terrenos de excepción en los que más fácilmente podrán entenderse, para colaborar, los historiadores con interés por las realidades y los geógrafos con curiosidad por los orígenes. ${ }^{33}$

Georges Duby, sin duda, coincidía con lo anterior pero, además, agregaba que un libro precursor, tan bello, tan importante, no podía uno más que convertirlo en libro de cabecera, cosa que él gustoso hizo, al grado de que cuando en una ocasión volvió a abrirlo encontró que casi sabía de memoria páginas completas. ${ }^{34}$

Bloch más o menos decía: Historia, ciencia del cambio, y como toda ciencia, llena de afirmaciones que no son más que hipótesis. Pero, ¿qué podemos decir acerca de su libro, modelo de investigación, $L a$ sociedad feudal (1938-9) que no se haya dicho ya? Bloch a su obra en general siempre la consideró incompleta, quizá pensaba un tanto como el poeta Roberto Juarroz, que un poema siempre será inacabado y es el lector quien está obligado a terminarlo. Después de todo Bloch también pensaba que la labor del historiador poseía algo de poesía y que había que hacer todo por evitar que la perdiese. $\mathrm{Al}$ respecto de este libro decía que le había ayudado a comprender que no existía sólo una civilización medieval, sino más bien muchas, sucesivas, y que, además, se trataba de un período que presenta prolongaciones en el tiempo. En efecto, las instituciones feudales en Europa, por ejemplo, eran semejantes, pero a partir de un estudio comparado, Bloch encuentra que "el Midi aquitano y la Normandía en Francia, que Italia del Norte y Alemania, que la Inglaterra anglosajona y la España de las monarquías asturleonesas a pesar de las condiciones de vida comunes a todo el Occidente, diferenciaron el régimen del feudo como consecuencia de circunstancias particulares". No obstante, reconoce que como Francia

${ }^{33}$ La historia rural francesa, op. cit., p. 14.

${ }^{34}$ Georges Duby..., La historia continúa, op. cit., p. 13. 
poseía una poderosa red de vasallaje, sus instituciones fueron llevadas a Inglaterra y a Italia del sur por los normandos e incluso a Siria por los cruzados. ${ }^{35}$ Así se lo indicó su enorme esfuerzo investigativo, que ni más ni menos consistió en realizar "el análisis y la explicación de una estructura social y sus relaciones”. Con tal ambición le resultó necesario desarrollar la obra en dos partes: la primera se encargó de estudiar las condiciones que regían al medio social así como la construcción de los lazos de dependencia de hombre a hombre, y la segunda contempló el desarrollo de las clases y su gobiernos. En sus propias palabras: "el primero será sobre todo el de la formación, y el segundo, el del desarrollo final y el de las supervivencias”. Asimismo lo consideró como un "ejemplo de algo que muy gustosamente denominaría desmonte de una estructura social”. En efecto, así también nos lo dice Duby, quien, en principio reconoce que dicha obra prácticamente le modeló la mente y lo marcó en su forma de escribir, pero también en sus elecciones. Al releerlo reconoce su audacia, su juventud, su fecundidad. Pero además, ¡qué más bello homenaje decir de él!: “Si tuviera que aconsejar una sola obra a los historiadores noveles sería ésta, pues estoy convencido de que les ayudará a llegar más lejos aún de lo que lo hemos hecho nosotros, gracias a las aventuradas propuestas que encierra y a todos los problemas, aún por resolver, que vemos planteados en ella.” Como toda obra clásica, permite muchas relecturas, y por eso también agrega Duby que de este trabajo "no dejo de aprender cada vez que lo releo”. ${ }^{36}$ Repetimos qué mayor homenaje para un hombre que escribió su libro deseando que sirviera 'para despertar el apetito', es decir, para despertar el 'hambre de aprender y sobre todo de buscar'.

Como hemos visto, Duby reconoce que Bloch le impactó con su forma de escribir. En efecto, acercándonos a la obra de Duby lo primero que salta a la vista es la sencillez de su expresión, casi coloquial. Pues ¿para qué ser pedantes e indigestos? Máxime cuando se trata de plati-

${ }^{35}$ Cfr. Marc Bloch, La sociedad feudal, prólogo de Henry Beer, 2002, Madrid, Akal, p. 15.

${ }^{36}$ Duby, op. cit., p. 14 y 15. 
car y confesar cómo fue su evolución particular muy marcada por la escuela inaugurada por Bloch y Febvre. Evolución particularmente inquieta, siempre insatisfecha y siempre buscando métodos, maneras, formas de análisis. Él mismo nos confiesa que inicialmente estuvo impactado por la historia económica, que relegaba a segundo plano a la historia social, pues primero se había formado con geógrafos. Pero poco después, por influencias directas de los Annales, decidió estudiar la organización social encastrada en lo rural, sin comerciantes, esto es, una historia del hombre en sociedad.

Pero como tuvo la necesidad de escribir una tesis y elegir un tema, ahora tenemos a un Duby explorando una obra de varios volúmenes: Recuil des chartes de l'abbaye de Cluny de Augustin Bernard. Así, nos encontramos con 'un paciente roturador' revisando 'títulos de propiedad y privilegios de una comunidad’ que en total sumaban más de cinco mil quinientos documentos. Estas fuentes, nos dice Duby, lo llevaron a decidirse por estudiar sobre todo los siglos XI y XII pero delimitándolos en un estrecho marco, donde el método comparativo de Marc Bloch no podía ayudarlo. Sin embargo, no olvidemos que Bloch también gustaba de animar los estudios locales, pues la suma de todos podía ayudar perfectamente a la historia comparada. Así que los 'pacientes roturadores' resultaban imprescindibles con sus trabajos de historia local a la que definía como "una cuestión de historia general planteada a los testimonios que proporciona un campo de experiencias restringido", ${ }^{37}$

Sin embargo, vemos que el 'paciente roturador’ de Duby a sus más de cinco mil quinientos documentos, obtenidos en las visitas de archivos y bibliotecas, ahora les agrega más de diez mil documentos referentes a múltiples vidas de monjes, a los que como él mismo reconoce, no logra hacer hablar del todo porque no sabe todavía interrogarlos.

La realidad de la vida social no se entrevé en el relato más que en algunos destellos fugitivos. En cuanto a la posibilidad de

${ }^{37}$ La historia rural..., op. cit., p. 49. Al respecto véase también la nota 32. 
JAVIER MEZA

descubrirla bajo la cobertura de los fantástico o en los intersticios de lo no dicho, eso ni lo soñaba aún. Entonces los historiadores no habían descubierto el interés de interpretar de esa manera los testimonios de ese tipo. ${ }^{38}$

Sin embargo, Duby tuvo que elegir entre aprender a manejar las herramientas de la investigación histórica (paleografía) o aprender a contar la historia, y terminó por elegir lo segundo. Es decir, el oficio que requiere de la paciencia y el análisis y en el que, como también dijera Bloch, en ocasiones necesitamos muchos días de análisis para obtener en un día un poco de síntesis. Oficio que también requiere observar, salir afuera del gabinete, porque a veces hasta un simple gesto de otro puede revelarnos mucho. Como dice Duby: "Admiro con mucho la paciencia de la que hice gala en mis comienzos, y aún más, mi audacia.” ¿Qué mejor ejemplo de enseñanza e imaginación para leer un documento que el que nos muestra el propio Duby al utilizar el juego de diferentes elementos?, porque la lectura de Duby constituye una suma de 'virutas' muy importantes del taller del historiador. Pero del Duby abrumado por los miles de documentos pasamos al Duby preocupado por la síntesis, es decir, lo que en realidad constituye el oficio de historiador. Una síntesis, una manera de escribir, una erudición que penetra en diferentes saberes para además de ser más brillante, preocuparse más por las relaciones que por los hechos. Así, de la economía y los estudios locales lo vemos pasar a la preocupación por estudiar las instituciones, el feudo y el vasallaje. Es decir, preocupado por comprender cómo se ejercía el poder de los ricos sobre los campesinos. Él mismo nos confiesa: "No tenía más apoyo que mi propia experiencia, lo que había aprendido explorando una zona rural muy restringida en un breve período. Necesitaba salir de esa estrechez, expansionarme...,” y la expansión consistía en leer nada menos casi todo lo que existía acerca del período entre el siglo VIII y el XV. Ahora

${ }^{38}$ Georges Duby, La historia..., op. cit., p. 31. 
tenemos a un Duby devorador de libros, ávido lector de ciento sesenta y seis publicaciones en las cinco lenguas que conocía. ${ }^{39}$

Como digno hijo de su tiempo, también nos confiesa que no pudo escapar a la seducción del marxismo, método al que no deja de reconocer lo mucho que le ayudó, sin embargo, es muy importante una de sus últimas recomendaciones: desconfiar de las teorías. Espíritu abierto, nos demuestra que el dogmatismo no se lleva con la ciencia, que como antes señalamos, en muchos sentidos no es más que hipótesis. Las teorías deben servir para jugar con ellas, no para tomarlas demasiado en serio, usarlas, sí, pero "con total libertad, como una herramienta más”. 40

Ciertamente, Duby es polifacético, a todo lo anterior habría que agregar el impulso que las ciencias sociales recibieron a través del estructuralismo, vía la antropología social, que él supo aprovechar muy bien. Para terminar quiero señalar su relación con el método comparativo y las mentalidades.

En su inmensa producción, considero que existe un libro clave para comprender la organización social y mental de la Edad Media, me refiero a Los tres órdenes o lo imaginario del feudalismo (1978) y que constituye, en gran medida, un merecido homenaje a Georges Dumézil (1898-1986), uno de los especialistas más grandes en mitología y filología comparada a nivel indoeuropeo, que descubrió la organización tripartita o trifuncional de las sociedades. Abreviando digamos que Dumézil encontró en la India, (posiblemente de origen indoiranio) una organización social tripartita basada en brahmanes (sacerdotes), ksatriya (guerreros) y vaisya (ganaderos o agricultores). Para sorpresa de todos, también encontró que dicha organización se repetía con los Nartos al norte del Caúcaso, Escitas y romanos, en donde el sacerdote-sabio representa la inteligencia, los guerreros la fuerza física y los productores la riqueza. ${ }^{41}$ Duby, inspirado por estos descubrimientos

${ }^{39}$ Cfr., ibid., p. 79 y 80.

${ }^{40}$ Ibid., p. 89. 
JAVIER MEZA

los rastreó en la Edad Media y pudo descubrir los discursos producidos por la Iglesia que fundaban el orden trifuncional basado en oratores, bellatores y laboratores, es decir, sacerdotes, guerreros y productores, y que el discurso dominante metafóricamente traducía como pastores, perros guardianes y rebaño. ${ }^{42}$

De la sociedad feudal, a nivel de su imaginario, la lingüística comparativa también ayudó a descubrir algo muy importante para los actos humanos: la concepción del tiempo, que no es igual en todos los grupos que integran una sociedad. Y es en este sentido la observación de Jacques Le Goff nos dice que:

Paul Imbs... subraya que en el curso de la Edad Media el lenguaje, al menos en Francia, se vuelve más claro, cada vez más diferenciado, para expresar la coincidencia, la simultaneidad, la posterioridad, la anterioridad, etc. También individualiza

${ }^{41}$ Georges Dumézil dirá que su enorme trabajo podía hacerlo merecedor de ocupar un lugar junto a los historiadores, pero advertía que sólo creía en aquellos "que se esfuerzan por todos los medios razonables por establecer, fechar, explicar hechos, pero que cuando se dan cuenta de que no tienen los medios precisos, rechazan el establecerlos, fecharlos o explicarlos”. Mito y Epopeya III: Historias Romanas, 1996, México, FCE, p. 10. Bloch recomendaba algo parecido cuando decía “... yo he procurado no disimular jamás, cualquiera que fuese su origen, las lagunas o las incertidumbres de nuestros conocimientos".

${ }^{42}$ Según Duby, Carlomagno recomendaba “que cada uno permanezca unánimemente en su propósito de vida y en su profesión”; y en otra parte también señala que: “Al amonestar al rey en 883 , como lo hará dos siglos más tarde Adalberón, el obispo de Lyon Agobardo... recomienda velar , 'ante los disturbios de esta época por lo que sea capaz cada uno de los órdenes, el militar y el eclesiástico, es decir, aquellos que sirven en la milicia secular y en el ministerio sagrado, unos combatiendo con el acero, los otros disputando con el verbo'. El acero, el verbo; las armas, la palabra. Hemos llegado a la formulación: ‘Unos combaten, otros oran'.” Los tres órdenes o lo imaginario del feudalismo, 1983, Barcelona, Argot, p. 109 y 122. Citado por Duby, el subrayado es suyo. 
modos de concebir y expresar la relación pasado/presente que cambian en función de las clases sociales: el tiempo de los filósofos, los teólogos y los poetas oscila entre la fascinación del pasado y el impulso hacia la salvación futura: tiempo de decadencia y de esperanza; el del caballero es el tiempo de la velocidad pero que a menudo gira en el vacío, confundiendo los tiempos; el tiempo del campesino es el tiempo de la regularidad y la paciencia, de un pasado donde se trata de mantener el presente; mientras el tiempo del burgués, naturalmente, es el que distingue cada vez más entre pasado/presente/(futuro), y se orienta más deliberadamente hacia el futuro. ${ }^{43}$

No obstante, es indudable que todo método posee sus riesgos y el comparativo no constituye una excepción. Uno de ellos puede desprenderse de la propia abundancia de concordancias respecto a un fenómeno histórico; ante tal situación no faltarían investigadores que a todos los trabajos pioneros los considerasen como inservibles y poco dignos de revisarse relegando así al olvido materiales que pueden ser invaluables. Otro problema vendría dado por creer que los materiales que existen son ya suficientes y sólo sería necesario plantear conclusiones. Pero como quiera que sea es innegable que la concepción y práctica del método comparativo por parte de Marc Bloch contribuyó y contribuye a la permanente construcción de la ciencia histórica. Como afirma Jacques Le Goff, Bloch fue uno de los primeros en utilizar este método aplicado a comparar fenómenos y sistemas históricos y fue una de sus obsesiones porque creía firmemente que de esta manera "el historiador podía abordar las generalidades que forman el esqueleto de la historia sometida por otra parte al azar y a la individualización, y a la vez reconocer la especificidad, la originalidad de cada época, cada sociedad, cada civilización". ${ }^{44}$ Pero, además, sin olvidar que el método crítico incluye entre sus recomendaciones principales la renuncia a las

43 Jacques Le Goff, Pensar la historia..., op. cit., p. 179.

44 Jacques Le Goff, prefacio a Apología para la historia..., op. cit., p. 48. 


\section{JAVIER MEZA}

mentiras que normalmente provienen del amor al lucro o a la gloria, al desprecio o a la amistad incondicional, y a los anhelos de notoriedad, es decir por sobre todo 'limpieza de la inteligencia'. 